\title{
99mTC(V)-DMSA SPECT-CT findings in a case of Gorham-Stout disease
}

Victor M. Alves ${ }^{1}$, Tiago S. Vieira' ${ }^{1}$, Nelson S. Amorim², Ana Oliveira ${ }^{1}$, André Rodrigues², Jorge G. Pereira $^{1}$

${ }^{1}$ Department of Nuclear Medicine, São João Hospital Center, Porto, Portugal

'Department of Orthopedics, São João Hospital Center, Porto, Portugal

The authors declare that they have no conflict of interest

[Received 2 II 2015; Accepted 15 IV 2015]

\begin{abstract}
The Gorham-Stout disease is a very rare condition, characterized by lymphovascular proliferation and massive bone resorption. We present a 48-year-old male patient with osteolysis involving the left femoral head and neck, as well as to the ipsilateral acetabulum. Besides the morphological imaging, he underwent bone scintigraphy, technetium-99m-V-dimercaptosuccinic acid [99m Tc(V)-DMSA] single photon emission computed tomography/computed tomography (SPECT/CT) and histological examination. Together these findings gave the definitive diagnosis. This is the first case ever published with ${ }^{99 m T c(V)-D M S A ~ S P E C T-C T . ~}$ Advances on the knowledge of disease suggests that this imaging procedure could have utility in diagnosis and evaluation of the disease activity and therapy response.
\end{abstract}

KEY words: ${ }^{99 m T c(V)-d i m e r c a p t o s u c c i n i c ~ a c i d, ~ b o n e ~ s c i n t i g r a p h y, ~ G o r h a m-S t o u t ~ d i s e a s e, ~ s i n g l e-p h o t o n ~ e m i s s i o n ~}$ computed tomography/computed tomography

Nuclear Med Rev 2015; 18, 2: 97-101

\section{Background}

The Gorham-Stout disease is a rare entity of unknown etiology, with no inheritance pattern $[1,2]$, and no gender or racial predilection [3]. It may occur at any age, but is most common among adolescents and young adults $[1,3,4]$. It is characterized by non-neoplastic proliferation of vascular or lymphovascular tissue, on a fibrous connective tissue matrix, associated with progressive bone resorption of one or more contiguous bones around one focus, which do not respect for joint boundaries $[3,5]$. It displays monocentric osteolysis, but may exceptionally appear as multicentric $[1,6]$. Although it may involve any part of the skeleton, the maxilla, mandible, clavicle, ribs, cervical vertebrae, pelvis and femur are the most common bones involved [4]. The disease has a progressive course, but it can reach a quiescent stage, in a spontaneous and unpredictable way, after which there is no bone regeneration [1, 7, 8]. Some Nuclear Medicine imaging procedures, such as bone scintigraphy, ${ }^{99 m} \mathrm{Tc}(\mathrm{V})$-DMSA scintigraphy and ${ }^{18} \mathrm{~F}$-FDG PET, were described as helpful in the diagnosis and assessment of disease extension and activity [9-14]. To the authors' knowledge, so far, only one case reporting the use of ${ }^{99 \mathrm{~m}} \mathrm{Tc}(\mathrm{V})$-DMSA scintigraphy was published [9]

Correspondence to: Victor M. Alves

Department of Nuclear Medicine

São João Hospital Center

Alameda Prof. Hernâni Monteiro

4200-319 Porto, Portugal

E-mail: victor_alves@outlook.pt
We present a case of multifocal Gorham-Stout disease involving the left femur, extending to the ipsilateral pelvis, evaluated by bone scintigraphy, ${ }^{99 m} \mathrm{Tc}(\mathrm{V})$-DMSA SPECT-CT, CT, MRI and histological examination.

\section{Case report}

A 48-year-old male patient presented with a prior history of intravenous drug abuse, smoking habits, spontaneously resolved hepatitis B and C, cryoglobulinemia, and a car accident in 2006. From the accident resulted a thoracic wall hematoma, complicated with infection and chronic osteomyelitis of the left $5^{\text {th }}$ and $6^{\text {th }}$ ribs, which were resected in the meantime. He had no known relevant family history or renal pathology.

The patient has presented a 4-year history of left hip pain, accompanied by progressive functional disability.

\section{Imaging findings}

In 2010, as a part of the initial diagnostic approach, the patient underwent a radiography, which revealed left coxarthrosis, and was then referenced to our department for performing a three-phase bone scintigraphy with SPECT of the hips. This revealed decreased tracer uptake in the left femoral head and neck, and dysmorphia of the hip joint. Subsequently, MRI (Fig. 1) showed an almost complete resorption of the left femoral head and neck, extending to the upper acetabular anterior column and the iliac wing, with no evidence of subcortical sclerosis, periosteal reaction, bone erosion, change of the bone marrow signal or joint effusion. The bone was apparently replaced by a soft tissue mass, hypointense at T1-weighted 

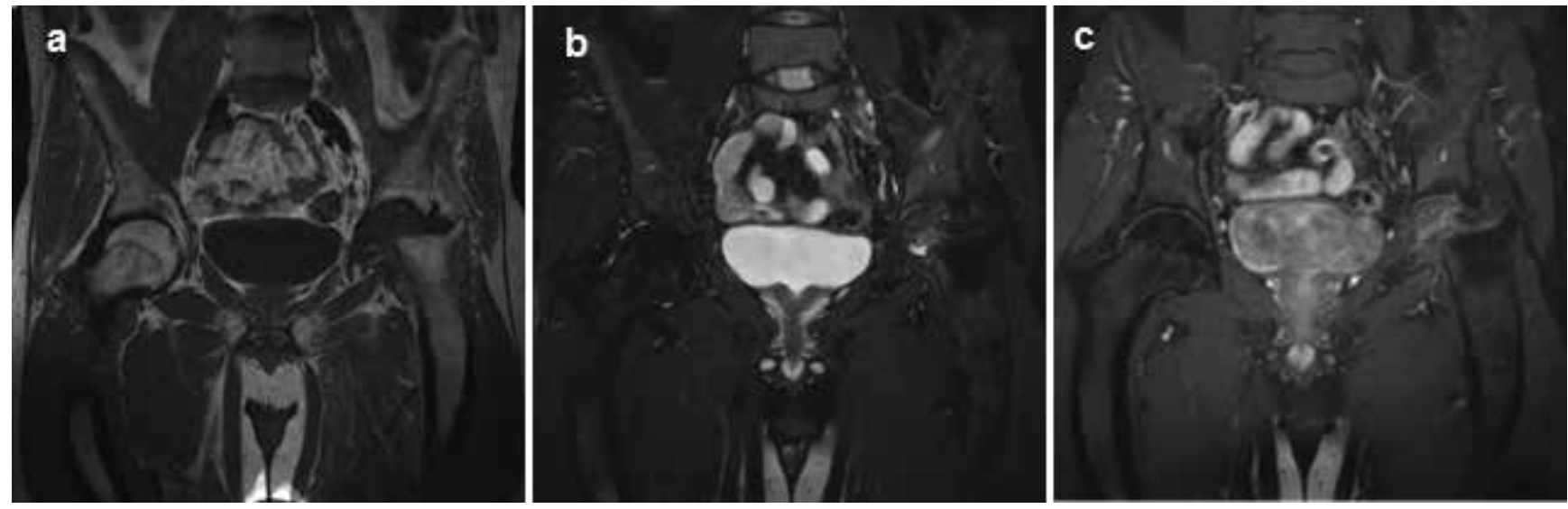

Figure 1A-C. MRI of hip joints; A. T1-weighted spin-echo; B. T2-weighted turbo spin echo with fat suppression imaging; C. Gadolinium-enhanced T1-weighted turbo spin echo with fat suppression. Almost complete resorption of the left femoral head and neck, extending to the upper acetabular anterior column and the iliac wing, and replacement by a soft tissue mass

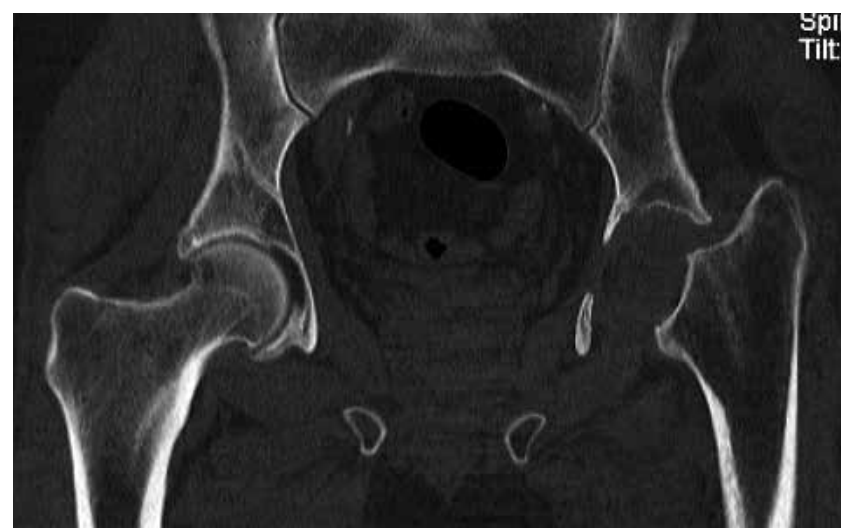

Figure 2. CT scan of hip joints. It confirmed the findings of MRI

image, with intermediate signal in T2-weighted and proton density images, and with mild and heterogeneous contrast uptake. In order to better characterize the findings and help to rule out avascular necrosis of the femoral head, CT (Fig. 2) was performed which was in accordance with the MRI diagnostic findings.

Alkaline phosphatase was elevated in successive tests during 2011. Since then, it has been normal. In 2013, a hip biopsy was carried out and the histological examination showed fibrous connective tissue with variable collagenous density, some areas of dense hyaline sclerosis and small vessels scattered. Bone was not identified.

The conjunction of the clinical, imaging and histological findings made the diagnosis of Gorham-Stout disease possible.

\section{Follow-up}

After the diagnosis, a watchful waiting was adopted. During follow-up there was a persistence of complaints.

\section{Bone scan}

In 2014, the patient was reevaluated with three-phase bone scintigraphy (Fig. 3) which maintained similar findings regarding the previous procedure over the left hip, but also revealed a new focus of increased tracer uptake in the lower third of the left femoral diaphysis.

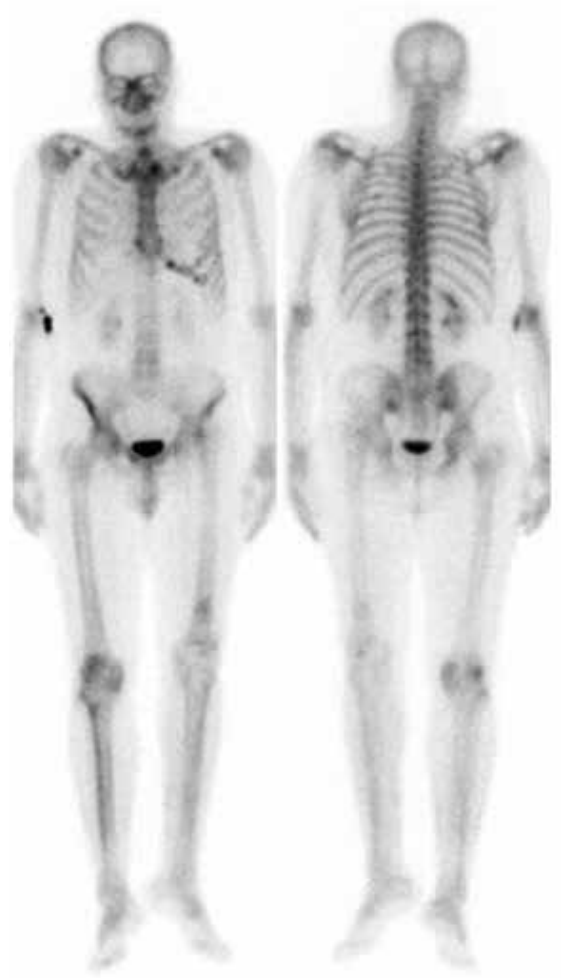

Figure 3. Whole body bone scintigraphy (2014) showing dysmorphia of left hip joint and mild decrease in tracer uptake involving adjacent bones, as well as a focal increased tracer uptake in the lower third of the left femur

\section{${ }^{99 m}$ Tc(V)-DMSA scintigraphy}

In order to evaluate the disease activity, a decision was made to perform whole body ${ }^{99 m} \mathrm{Tc}(\mathrm{V})$-DMSA scintigraphy (Fig. 4A) with SPECT-CT of the hips (Fig. 4B). The images were obtained in a dual-head gamma camera (GE Infinia Hawkeye $4^{\circledR}$ ) equipped with low-energy high-resolution collimators and a four-slice CT scanner. The patient underwent an intravenous injection of $740 \mathrm{MBq}{ }^{99 \mathrm{~m}} \mathrm{Tc}(\mathrm{V})$ -DMSA and after 2 h 30 min, a whole body scintigraphy was performed (scanning speed $10 \mathrm{~cm} / \mathrm{min}$ ). The SPECT/CT was acquired 

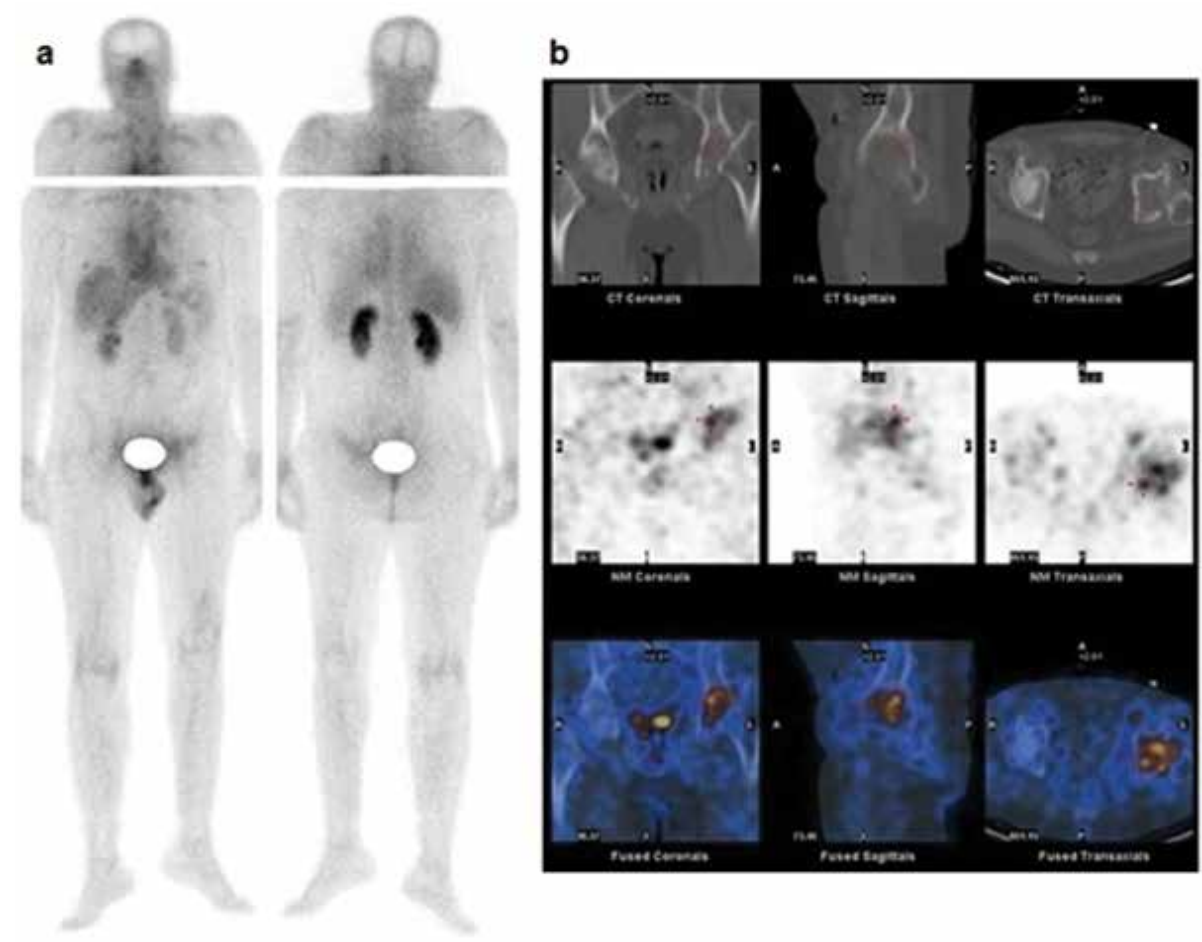

Figure 4A. ${ }^{99 \mathrm{~m} T c(V)-D M S A}$ scintigraphy showing an increased tracer uptake in the left hip joint, and lower third of the left femur. Note: Due to claustrophobia, the patient did not conclude the whole body scan and a spot view of the head region was necessary; B. ${ }^{99 m}$ Tc(V)-DMSA SPECT-CT of hip joints revealing increased tracer uptake involving the left femoral head and neck and ipsilateral acetabulum

immediately after planar images (SPECT: step-and-shoot $3^{\circ} / 3^{\circ}$, orbit $360^{\circ}, 25$ s/projection, matrix $64 \times 64$, zoom 1.0; CT: $140 \mathrm{kV}$, $2.5 \mathrm{~mA}$ ). This exam revealed increased tracer uptake in the same topography of the low density lesions (as seen in the low-dose CT) in the left femoral head and neck and ipsilateral acetabulum, which also coincided with the regions of decreased tracer uptake seen in the bone scintigraphy. Additionally, increased and heterogeneous uptake was evidenced on the lower third of the left femoral diaphysis, in the same area of increased ${ }^{99 \mathrm{~m} T c-H D P}$ uptake.

The persistence of complaints, the appearance of a new lesion in the left femur and an increased ${ }^{99 \mathrm{~m}} \mathrm{Tc}(\mathrm{V})$-DMSA uptake in lytic lesions of the hip and distal femur, as well as histological evidence of vascular proliferation (instead of only fibrous tissue) in the lesions in the left hip, were all in favor of persistent disease activity. A non-invasive therapeutic approach with bisphosphonates was chosen, in order to induce remission, and then to attempt total hip arthroplasty.

\section{Discussion}

The Gorham-Stout disease is a rare condition, with around 300 cases published in the literature [4], since its first description by Gorham and Stout, 50 years ago [5].

The diagnosis requires a conjunction of clinical, imaging and histological findings, as well as the exclusion of any other cause of primary or secondary osteolysis [3, 15-17].

Clinical presentation is variable and depends, in part, on the body region involved [2]. Some patients may be asymptomatic until undergoing a fracture triggered by minor trauma $[4,18]$, whereas others complain of localized pain, edema, progressive deformity, contractures, muscle atrophy and functional disability $[3,2]$.
The extension of the disease from the ribs, sternum, scapula or vertebrae to the mediastinum, with the invasion of the thoracic duct, can lead to pleural or chylous pericardial effusion, and respiratory and cardiac failure, respectively [18-22]. Paraplegia may occur in cases involving the spine, with vertebral fracture and spinal cord compression [23]. The case we report is mainly characterized by the involvement of the left hip joint, resulting in prominent pain and functional disability of that joint.

In the early stage of the disease, the radiographic features are radiolucent foci in the intramedullary and subcortical regions. As the disease progresses, these foci enlarge and coalesce, and there is cortical and, eventually, adjacent soft tissue involvement. Concentric retraction is also noticed, giving it a "sucked candy" appearance. In several cases, bone dissolution progresses until a portion or the whole bone has been reabsorbed and replaced by fibrous tissue. Fracture, fragmentation and soft tissue atrophy may occur. The process can also extend to adjacent bones [2, 4, 24]. Usually there is no bone sclerosis or periosteal reaction, though it has been described [25].

In two previous reports, magnetic resonance imaging revealed a lesion, iso- or hypointense at T1-weighted image and hyperintense at T2-weighted image and a reticular pattern in the contrast study $[18,26]$.

Radiographic features of osteolysis in our case were similar to those described in the literature. The absence of marginal sclerosis, periosteal reaction or bone regeneration was useful in the differential diagnosis with other causes of osteolysis. Magnetic resonance findings partially agreed with previous reports. The T1-weighted and contrast study presented similar findings, but the T2-weighted study showed an intermediate signal instead of the hyperintense signal previously reported $[18,26]$. 
The changes described in literature addressing bone scintigraphy are variable. It has been described an increased tracer uptake in the vascular and blood pool phases, and a decreased late bone uptake, eventually with a high marginal uptake [2, 11, 12], or else an increased tracer uptake throughout the lesion, in the bone phase $[1,25]$. In our case, bone scintigraphy showed a different pattern of low tracer uptake in the initial phases, although also a decreased tracer uptake in the bone phase, as previously documented. The appearance of a second femoral lesion separated from the former one by normal bone is very rare and a sign of disease activity $[1,3]$.

Until now, only one case using ${ }^{99 m} \mathrm{Tc}(\mathrm{V})$-DMSA scintigraphy was published, showing intense uptake in the multiple osteolytic lesions [9]. The ${ }^{99 \mathrm{~m}} \mathrm{Tc}(\mathrm{V})-\mathrm{DMSA}$ is a nonspecific tumor-seeking agent, initially used for the evaluation of medullary thyroid carcinoma. Its usefulness has also been reported in the evaluation of many other types of cancer, such as head and neck, soft tissue, and breast $[27,28]$. Its mechanism of uptake is thought to be due to the structural similarity between ${ }^{99 m} \mathrm{Tc}-(\mathrm{V}) \mathrm{DMSA}$ core (phosphate-like ion $\mathrm{TcO}_{4}^{-3}$ ) and phosphate $\left(\mathrm{PO}_{4}{ }^{-3}\right)$ anion [28] It is considered that ${ }^{99 \mathrm{~m} T c}(\mathrm{~V})$-DMSA enters the cells through the type III NaPi co-transporter [27]. Activated platelet-derived growth factor receptor (PDGF-R) appears to be involved in this transport mechanism [27] and an experimental model showed that PDGF-BB is a strong stimulator of the type III NaPi co-transporter [29]. It is worthy to note that expression of the platelet-derived growth factor beta receptor (PDGFR- $\beta$ ) and of the platelet-derived growth factor-BB (PDGF-BB) was noticed in a case of Gorham's disease [30]. Since the PDGFR-b is an important lymphangiogenic factor [31], this finding suggests this signal pathway may be involved in the development of the disease.

It is also interesting that the inhibitor of PDGF-R tyrosine kinase, imatinib, suppresses the expression of type III NaPi co-transporter, as well as ${ }^{99 m} \mathrm{Tc}(\mathrm{V})$-DMSA uptake in vitro [27]. Other studies showed a relation between the in vivo ${ }^{99 m} \mathrm{Tc}(\mathrm{V})$-DMSA uptake and the proliferation rate measured by the expression of Ki-67 and by the phosphorylated focal adhesion kinase [27]. It was also described an inverse relation between $\mathrm{pH}$ and ${ }^{99 \mathrm{~m}} \mathrm{Tc}(\mathrm{V})$-DMSA uptake, where glucose-mediated acidosis stimulated ${ }^{99 m} \mathrm{Tc}(\mathrm{V})$-DMSA uptake [28].

Several mechanisms were proposed for explaining bone resorption, including the lymphovascular proliferation, the increase in number and/or activity of osteoclasts and the decrease of osteoblastic activity. Abnormal vascular proliferation may promote osteolysis directly by bone compression, indirectly by secretion of factors that influence the osteoblastic and/or osteoclastic activity, or even more indirectly by reducing blood flow in abnormal vessels, leading to hypoxia with subsequent $\mathrm{pH}$ decreasing and increased hydrolytic enzyme activity $[4,18]$. Lymphangiogenesis may be promoted by growth factors in a microenvironment of activated receptors, on the surface of lymphatic endothelial cells. In addition to the PDGF-R pathway, which was already stressed, the vascular endothelial growth factor family can also be involved [4]. There are a few reports of increased serum VEGF-C, as well as of increased serum and plasma VEGF-A, in patients with Gorham-Stout disease [4].

Since ${ }^{99 m} \mathrm{Tc}(\mathrm{V})$-DMSA uptake depends on the expression of platelet-derived growth factor receptor (including the beta subtype - PDGFR- $\beta$ ) and likely of PDGF-BB, and since the expression of both seems to be increased in Gorham-Stout disease, this could explain an increased ${ }^{99 m} \mathrm{Tc}(\mathrm{V})$-DMSA uptake in this pathology. On the other hand, because in a late stage of the disease, the fibrovascular tissue from the lytic region is replaced by fibrous tissue [32], and the ${ }^{99 m} \mathrm{Tc}(\mathrm{V})-\mathrm{DMSA}$ uptake seems to depend on the presence of lymphovascular tissue, this radiopharmaceutical may be of particular value to assess disease activity. On the other hand, $\mathrm{Ki}-67$ expression, a cellular proliferation marker, is not increased in Gorham-Stout disease and probably do not have an important role in ${ }^{99 m} \mathrm{Tc}(\mathrm{V})$-DMSA uptake. The ${ }^{99 \mathrm{~m}} \mathrm{Tc}(\mathrm{V})$-DMSA scintigraphy may have value in the diagnosis, evaluation of disease extension and activity, therapeutic response assessment and research of new therapeutic agents efficacy, such as, imatinib [30].

Meanwhile, there is no entirely effective therapy $[2,7]$. Surgical treatment consists in the resection of the affected bone and, eventually in the placement of a bone graft or prosthesis. In cases requiring arthroplasty, the appropriate resection of the complete extension of the lesion ensures a good prognosis without recurrence, even in those cases where the disease was still active at the moment of intervention [3]. Regarding medical treatment, the benefit of external radiotherapy, bisphosphonates and interferon alpha-2b, was described [3]. Radiotherapy can be used in combination with surgery [33].

In conclusion, we reported a very rare case of Gorham-Stout disease, probably multifocal. This is the first case evaluated by ${ }^{99 \mathrm{~m} T c}$ (V)-DMSA SPECT-CT. This imaging procedure was important to evaluate activity, extension and multifocality of the disease. The current knowledge of Gorham-Stout disease and of the ${ }^{99 \mathrm{~m}} \mathrm{Tc}(\mathrm{V})$ -DMSA uptake mechanism suggests that the augmented uptake might result from increasing local expression of PDGFR- $\beta$ and PDGF-BB, as well as from a decreased tissue $\mathrm{pH}$. The demonstration of this may assign further value to ${ }^{99 \mathrm{~m}} \mathrm{Tc}(\mathrm{V})$-DMSA scintigraphy in diagnosing and evaluating disease activity, disease extension, and therapeutic response, as well as in evaluating new effective therapeutic agents.

\section{References}

1. Ozbayrak M, Yilmaz MH, Kantarci F et al. A case of an idiopathic massive osteolysis with skip lesions. Korean J Radiol. 2013; 14: 946-950. doi: 10.3348/kjr.2013.14.6.946.

2. Patel DV. Gorham's disease or massive osteolysis. Clin Med Res 2005; 3: 65-74.

3. Möller G, Priemel M, Amling M et al. G. The Gorham-Stout syndrome (Gorham's massive osteolysis) findings. J Bone Jt Surg (Br) 1999; 81: 501-506.

4. Dellinger MT, Garg N, Olsen BR. Viewpoints on vessels and vanishing bones in Gorham-Stout disease. Bone 2014; 63: 47-52. doi: 10.1016/j. bone.2014.02.011.

5. Gorham LW, Stout AP. Hemangiomatosis and its relation to massive osteolysis. Trans Assoc Am Physicians 1954; 67: 302-307.

6. Scialpi L, Servedio M, Moretti B et al. Gorham's disease: a rare case of multicentric localization. Chir Organi Mov 2004; 89: 339-345.

7. Dunbar SF, Rosenberg A, Mankin H, Rosenthal D, Suit HD. Gorham's massive osteolysis: the role of radiation therapy and a review of the literature. Int J Radiat Oncol Biol Phys 1993; 26: 491-497.

8. Tilling G, Skobowytsh B. Disappearing bone disease, morbus Gorham. Report of a case. Acta Orthop Scand 1968; 39: 398-406.

9. Kobayashi $\mathrm{H}$, Shigeno $\mathrm{C}$, Sakahara $\mathrm{H}$ et al. Intraosseous hemangiomatosis: technetium-99m(V)dimercaptosuccinic acid and technetium-99m-hydroxymethylene diphosphonate imaging. J Nucl Med 1994; 35: $1482-1484$. 
10. Spieth ME, Greenspan A, Forrester DM et al. Gorham's disease of the radius: radiographic, scintigraphic, and $\mathrm{MRI}$ findings with pathologic correlation. A case report and review of the literature. Skeletal Radiol 1997; 26: 659-663.

11. Othman S. Absent right iliac bone on Tc99m MDP bone scan in a patient with Gorham's vanishing bone disease. Indian J Nucl Med 2010; 25: 23-24. doi: 10.4103/0972-3919.63596.

12. López VL, Navarro P, Rodríguez CL et al. Gorham's disease: 99mTc HMDP bone scan findings. Rev Esp Med Nucl Imagen Mol 2012; 31: 292-294. doi: 10.1016/j.remn.2011.11.010.

13. Yang R-H, Chen PC-H, Chang C-P, Wang S-J. Gorham's disease: the disappearing bone. Clin Nucl Med 2013; 38: 361-364. doi: 10.1097/RLU.0b013e318286bf93.

14. Malde R, Agrawal HM, Ghosh SL, Dinshaw KA. Vanishing bone disease involving the pelvis. J Cancer Res Ther 2005; 1: 227-228.

15. Reddy S, Jatti D. Gorham's disease: a report of a case with mandibular involvement in a 10-year follow-up study. Dentomaxillofac Radiol 2012; 41: 520-524. doi: 10.1259/dmfr/93696387.

16. Lala S, Mulliken JB, Alomari Al et al. Gorham-Stout disease and generalized lymphatic anomaly — clinical, radiologic, and histologic differentiation. Skeletal Radiol 2013; 42: 917-924. doi: 10.1007/s00256-012-1565-4.

17. Hardegger F, Simpson LA, Segmueller G. The syndrome of idiopathic osteolysis. Classification, review, and case report. J Bone Joint Surg Br 1985; 67: 88-93

18. Lo C, Chen C-Y, Chin S et al. Disappearing calvarium in Gorham disease: MR imaging characteristics with pathologic correlation. AJNR Am J Neuroradiol 2004; 25: 415-418.

19. Duffy BM, Manon R, Patel RR, Welsh JS. A case of Gorham's disease with chylothorax treated curatively with radiation therapy. Clin Med Res 2005; 3: 83-86.

20. Takahashi A, Ogawa C, Kanazawa T et al. Remission induced by interferon alfa in a patient with massive osteolysis and extension of lymph-hemangiomatosis: a severe case of Gorham-Stout syndrome. J Pediatr Surg 2005; 40: E47-E50. doi: 10.1016/j.jpedsurg.2004.11.015

21. Boyle MJ, Alison P, Taylor G, Lightbourne BA. A case of Gorham's disease complicated by bilateral chylothorax. Heart Lung Circ 2008; 17: 64-66.
22. Noda M, Endo C, Hoshikawa Y et al. Successful management of intractable chylothorax in Gorham-Stout disease by awake thoracoscopic surgery. Gen Thorac Cardiovasc Surg 2013; 61: 356-358. doi: 10.1007/s11748012-0130-3.

23. Sekharappa V, Arockiaraj J, Amritanand R et al. Gorham's disease of spine. Asian Spine J 2013; 7: 242-247. doi: 10.4184/asj.2013.7.3.242.

24. Van der Linden-van der Zwaag H, Onvlee GJ. Massive osteolysis (Gorham's disease) affecting the femur. Acta Orthop Belg 2006; 72: 261-268.

25. Silva S. Gorham-Stout disease affecting both hands: stabilisation during biphosphonate treatment. Hand (NY) 2011; 6: 85-89. doi: 10.1007/s11552010-9292-6

26. Yoo SY, Hong SH, Chung HW, Choi J-A, Kim CJ, Kang HS. MRI of Gorham's disease: findings in two cases. Skeletal Radiol. 2002; 31: 301-306.

27. Al-Saeedi FJ, Mathew PM, Luqmani YA. Assessment of Tracer 99mTc(V)-DMSA uptake as a measure of tumor cell proliferation in vitro. PLoS One 2013; 8: e54361. doi: 10.1371/journal.pone.0054361. doi: 10.1371/journal. pone.0054361.

28. Al-Saeedi F. Role of 99mTc-(V)DMSA in detecting tumor cell proliferation. Anal Chem Insights 2007; 13: 81-83.

29. Kakita A, Suzuki A, Nishiwaki K et al. Stimulation of Na-dependent phosphate transport by platelet-derived growth factor in rat aortic smooth muscle cells. Atherosclerosis 2004; 174: 17-24

30. Hagendoorn J, Padera TP, Yock TI et al. Platelet-derived growth factor receptor-beta in Gorham's disease. Nat Clin Pract Oncol 2006; 3: 693-697.

31. Miyazaki $H$, Yoshimatsu $Y$, Akatsu $Y$ et al. Expression of PDGFR $\beta$ is maintained by Prox 1 in lymphatic endothelial cells and is required for tumor lymphangiogenesis. Cancer Sci 2014; 105: 1116-1123. doi: 10.1111/cas.12476.

32. Kilicoglu ZG, Kizildemir KN, Vardar AF et al. Gorham disease of the craniocervical junction: X-ray, computed tomography, and magnetic resonance imaging findings. Spine J 2013; 13: e11-e14. doi: 10.1016/j. spinee.2013.01.039

33. Browne JA, Shives TC, Trousdale RT. Thirty-year follow-up of patient with Gorham disease (massive osteolysis) treated with hip arthroplasty. J Arthroplasty. 2011; 26: 339.e7-e10. doi: 10.1016/j.arth.2010.03.003. 